\title{
Proposta de um sensor optoacústico para detecção em tempo real de moscas-das-frutas (Diptera: Tephritidae) para uso em armadilhas inteligentes
}

\author{
Fabiano Sandrini Moraes ${ }^{1}$, Dori Edson Nava ${ }^{2}$, Vagner Santos da Rosa ${ }^{1}$ \\ ${ }^{1}$ Centro de de Ciências da Computação - Universidade Federal do Rio Grande(FURG) \\ Av. Itália km 8 - Rio Grande - RS - Brasil \\ ${ }^{2}$ Embrapa Clima Temperado \\ BR 392 Km 78 - Pelotas - RS - Brasil \\ fabianomoraes@pelotas.ifsul.edu.br, dori.edson-nava@embrapa.br, \\ vsrosa@gmail.com
}

\begin{abstract}
This work presents the initial development of an optoacoustic sensor to be used in intelligent traps with real-time detection of fruit flies Ceratitis capitata and Anastrepha fraterculus. For this, a prototype of a sensor and the hardware for signal processing generated were developed. The initial sensor performance was evaluated through simulated experiments in the laboratory, where the sensor proved to be promising for tests with the insects of interest
\end{abstract}

Resumo. Este trabalho apresenta o desenvolvimento inicial de um sensor optoacústico para ser usado em armadilhas inteligentes com detecção em tempo real de moscas-das-frutas Ceratitis capitata $e$ Anastrepha fraterculus. Para isto foi desenvolvido o protótipo de um sensor para ser utilizado em uma armadilha do tipo McPhail, juntamente com o hardware para tratamento do sinal gerado pelo sensor. O desempenho inicial do sensor foi avaliado através de experimentos simulados em laboratório, onde o sensor mostrou-se promissor para testes com os insetos de interesse.

\section{Introdução}

As moscas-das-frutas são consideradas as principais pragas que afetam a fruticultura em nível mundial causando danos diretos e indiretos na produção. No Brasil, as principais espécies de moscas-das-frutas de importância econômica pertencem a três gêneros: Anastrepha, Bactrocera e Ceratitis. Dentre as espécies de moscas-das-frutas presentes no Brasil, as que apresentam restrições quarentenárias para os países importadores são: Anastrepha fraterculus (Wiedemann, 1830), Anastrepha obliqua (Macquart, 1835), Anastrepha grandis (Macquart, 1846), Ceratitis capitata (Wiedemann, 1824) e Bactrocera carambolae (Drew e Hancock, 1994) [Malavasi and Nascimento 2003].

Dados do Ministério da Agricultura, Pecuária e Abastecimento (MAPA) mostram que as moscas-das-frutas causam um prejuízo anual de até US\$ 120 milhões aos produtores brasileiros entre perdas de produção e custos de controle. A presença das moscas também inviabiliza a exportação de frutas frescas para mercados mais exigentes e rentáveis como Japão, Estados Unidos e Chile [MAPA 2015]. 
As moscas-das-frutas possuem ampla distribuição geográfica e uma grande quantidade de hospedeiros. Na região Sul do Brasil a A. fraterculus desenvolve-se em diversas frutíferas podendo inviabilizar a produção caso medidas de controle não sejam adotadas [Nava and Botton 2010].

O controle de moscas-das-frutas é feito de forma desregrada pelos fruticultores utilizando inseticidas na forma de iscas-tóxicas ou por cobertura sem conhecimento da espécie infectante, dos níveis de infestação e da distribuição dos hospedeiros. Este tipo de controle tem várias consequências indesejáveis como impacto ambiental, diminuição na qualidade fruto, restrições de exportação pela presença de resíduos químicos e um aumento no custo de produção [Nava and Botton 2010].

Dentre as alternativas para auxiliar no manejo das moscas-das-frutas, atualmente esforços estão sendo direcionados para as tecnologias utilizadas na Agricultura de Precisão. Destas tecnologias pode-se citar a que utiliza um conjunto de ferramentas que combina sensores, sistemas de informação, máquinas adaptadas e gestão de conhecimento para aperfeiçoar a produção e minimizar a variabilidade e incerteza em sistemas agrícolas, proporcionando meios para garantir a qualidade alimentar [Gebbers and Adamchuk 2010].

Para o manejo de mosca-das-frutas, dentre as técnicas propostas pela agricultura de precisão é fundamental a realização do monitoramento por meio do usos de armadilhas iscadas com atratívos. Um dos possíveis tipos de armadilhas é a McPhail que usa atrativos alimentares para capturar adultos de moscas-das-frutas, Figura 1. Também é possível o uso de feromônios sexuais para atrair adultos e neste caso cita-se o exemplo do paraferomônio utilizado em armadilhas Deltas para atrair C. capitata. Quando as armadilhas são utilizadas para monitoramento é necessário que um técnico realize a inspeção das armadilhas fazendo a classificação e contagem das moscas capturadas [Nava and Botton 2010].

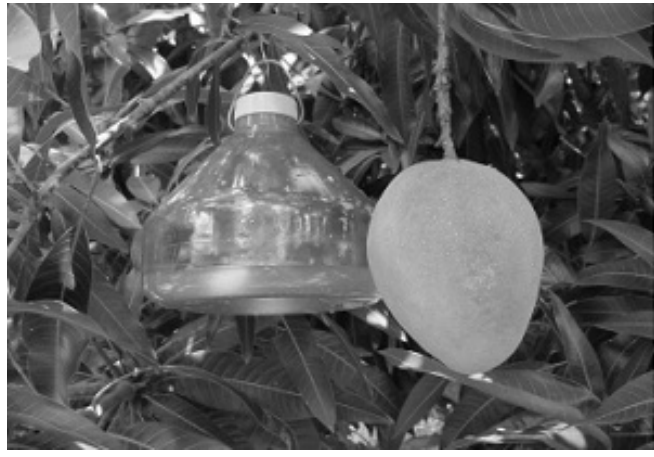

(a) Armadilha McPhail em uso

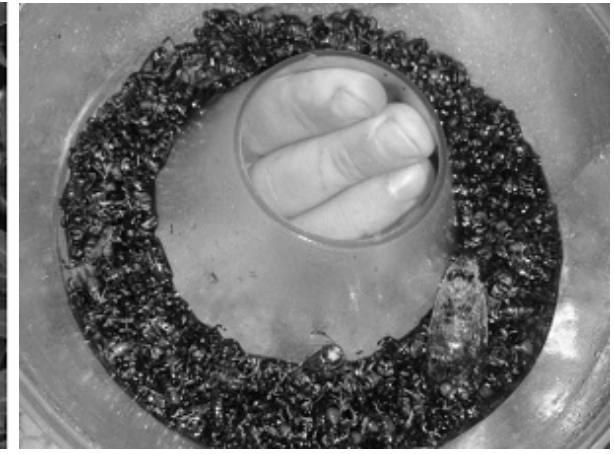

(b) Base da armadilha McPhail com moscas capturadas

Figura 1. Armadilha McPhail

Assim o presente trabalho apresenta o desenvolvimento de um sensor optoacústico para ser utilizado na concepção de uma armadilha de monitoramento inteligente, identificando e contando automaticamente as moscas-das-frutas capturadas. Assim, o sistema irá diminuir a necessidade da intervenção do técnico no monitoramento, contribuindo para minimização do erro humano na identificação e contagem das moscas e uma redução no 
custo do programa de monitoramento. O sistema poderá ser utilizado tanto como meio auxiliar para corroborar o levantamento realizado pelo técnico, como poderá ser meio principal em situações que há dificuldades para a presença do técnico. Esta tecnologia poderá ser integrada a um sistema de informações de apoio ao produtores rurais para a escolha de uma técnica efetiva no controle da praga. Como também ser utilizada por entidades para um mapeamento da evolução da praga.

\section{Materiais e Métodos}

Existem diversas tecnologias para identificação e detecção automática de insetos, mas as duas principais são os sensores acústicos e os sistemas de visão computacional [Liu et al. 2017].

$\mathrm{Na}$ tecnologia acústica estão sendo realizados estudos recentes utilizando sensores acelerômetros, sensores piezoelétricos, microfones e transdutores ultrassônicos. O uso de sensores acelerômetros e piezoelétricos é associado a detecção de insetos por vibrações no solo, em grãos a granel ou tecidos vegetais. Os sensores ultrassônicos são indicados para detecção em madeira. Os microfones são mais indicados para captação de sons ambiente como o de insetos durante o voo, sendo um método que apresenta uma grande sensiblidade ao ruído ambiente [Liu et al. 2017].

Como opção ao uso de microfones foi apresentado em [Unwin and Ellington 1979] o uso de sensores optoacústicos. Estes sensores medem a varią̧ão da luz causada pelo batimento das asas dos insetos convertendo está variação em um sinal elétrico com as mesmas características do sinal gerado pelo microfone.

Conforme [Potamitis et al. 2014], existem claras vantagens no uso de optoeletrônicos em vez de microfones:

- O dispositivo optoeletrônico capta o sinal somente quando o caminho do emissor para o receptor é interrompido enquanto um microfone capta o som de todas as direções;

- Sensores optoeletrônicos possuem uma relação sinal/ruído muito alta (são praticamente imunes a ruídos) enquanto que os microfones gravam todas as fontes de som (por exemplo, aves, cigarras, vento) e, portanto, as gravações podem se tornar muito ruidosas;

- Microfones, embora possam ser protegidos de várias maneiras contra as condições climáticas, são mais vulneráveis as condições de campo aberto;

- Possui um custo mais elevado.

Deste modo, optou-se pelo desenvolvimento de um sensor optoacústico para captar o som gerado pelo batimento das asas das moscas-das-frutas.

\subsection{Sensor Optoacústico}

O sensor proposto foi baseado no apresentado em [Potamitis et al. 2014] e [Potamitis et al. 2017]. Nestes artigos são mostradas as etapas do desenvolvimento de uma armadilha inteligente para para moscas-das-frutas da oliveira Bactrocera oleae.

O projeto da base do sensor e modelo 3D foi desenvolvido utilizando o software SolidWorks 2016. Estipulou-se para as dimensões da abertura de passagens das moscas 
$6,5 \mathrm{~cm}$ para a largura (l) e $6,5 \mathrm{~cm}$ para o comprimento (c), conforme apresentado na Figura 2. Estas dimensões foram baseadas nas dimensões do orifício de passagem de uma armadilha McPhail, possibilitando assim a acoplagem do sensor a armadilha.

$\mathrm{Na}$ definição da altura (h) levou-se em consideração o tempo de aquisição de $100 \mathrm{~ms}$ sugerido por [Potamitis et al. 2017] e a velocidade de voo de $0,25 \mathrm{~m} / \mathrm{s}$ obtida em [Vogel 1966]. Deste modo, a altura mínima é dada por

$$
h=\frac{0,25 m}{s} 0,1 s=2,5 \mathrm{~cm}
$$

Com base na altura mínima $\mathrm{h}=2,5 \mathrm{~cm}$ obtida na equação 1 , utilizou-se $3,0 \mathrm{~cm}$ para a altura, devido a existêcia da variação dos parâmetros de voo devido as condições climáticas conforme [Meng et al. 2017]. O parâmetro indicado é apresentado na Figura 2.

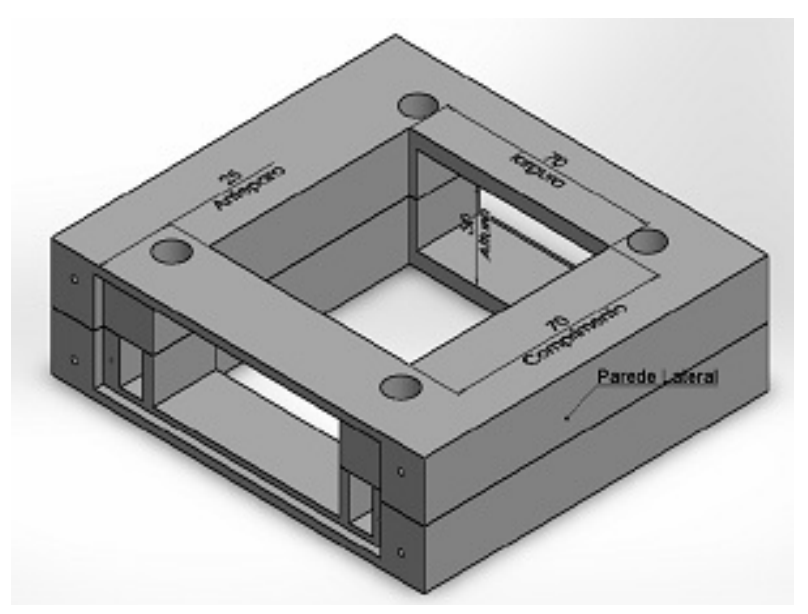

Figura 2. Projeto da base do sensor optoacústico com suas dimensões principais

Para diminuir a possibilidade de ruído gerado por interferência de luzes externas ao sensor foi inserido um anteparo de $2,0 \mathrm{~cm}$ e colocadas paredes laterais, conforme apresentado na Figura 2. Deste modo, tanto o emissor quanto o receptor ficam isolados da luz do ambiente.

Na construção da base do sensor optoacústico utilizou-se uma impressora 3D xyz Da Vinci 1.0, com um filamento de PLA. Configurada para uma impressão com preenchimento de $50 \%$ estilo colmeia, casca grossa, altura da camada de $0,1 \mathrm{~mm}$ e velocidade lenta.

Em relação ao circuito emissor foram utilizados LED-IR TIL32 como fonte de luz. Estes LED-IR tem como características principais o comprimento de onda de $940 \mathrm{~nm}$, ângulo de dispersão da luz de $35^{\circ}$, corrente direta de $20 \mathrm{~mA}$ e tensão direta de $1,3 \mathrm{~V}$.

Deste modo, considerando o ângulo de dispersão da luz do TIL32(35 $)$, o tamanho do anteparo(25mm), a altura da zona de passagem $(30 \mathrm{~mm})$, a ligação em série dos LED-IR e que a menor tensão de alimentação do circuito sendo de $8 \mathrm{~V}$. Determinou-se o número 
de linhas da matriz do circuito emissor por

$$
N^{\circ} \text { Linhas }=\frac{30 \mathrm{~mm}}{\tan 17,5^{\circ} .25 \mathrm{~mm}}=3,8
$$

para garantir a presença de luz em toda a zona de passagem arredondou-se para $4 \mathrm{o}$ número de linhas da matriz do circuito emissor.

Determinou-se o número de colunas da matriz do emissor por

$$
N^{\circ} \text { Colunas }=\frac{8 V}{1,3 V}=6,15
$$

para garantir que a tensão necessária no acionamento dos LED-IR não ultrapasse os $8 \mathrm{~V}$ de alimentação arredondou-se para 6 o número de colunas da matriz do circuito emissor. Assim, implementou-se a matriz do circuito emissor com 4 linhas e 6 colunas.

Para o circuito receptor utilizou-se como elementos receptores fototransistores TIL78 ligados em paralelo no modo fotovoltaico. O TIL78 tem como características comprimento de onda de $940 \mathrm{~nm}$, corrente gerada com luz de $1 \mathrm{~mA}$, corrente de escuro de 20nA e ângulo de recepção de $40^{\circ}$.

Assim, definiu-se a matriz do circuito receptor levando em consideração a largura da passagem(70mm), o tamanho do anteparo( $25 \mathrm{~mm})$ e o ângulo de recepção de luz $\left(40^{\circ}\right)$.

O número de colunas da matriz do circuito receptor do sensor é dado por

$$
N^{\circ} \text { Colunas }=\frac{70 \mathrm{~mm}}{\tan 20^{\circ} .25 \mathrm{~mm}}=7,69
$$

para garantir que não ocorra áreas de sombra na zona de passagem arredondou-se para 8 o número de colunas da matriz do circuito receptor.

Buscando-se a simetria entre o número de linhas do circuito receptor e do circuito emissor, definiu-se com 4 linhas a matriz do circuito receptor. Assim, implementou-se a matriz do circuito receptor com 4 linhas e 8 colunas.

Na Figura 3(a) é apresentado o detalhe da montagem dos circuito do emissor(esquerda) e o circuito do receptor(direita) e na Figura 3(b) é apresentado o sensor finalizado.

\subsection{Hardware Sensor Optoacústico}

O diagrama em blocos do hardware proposto para tratamento do sinal gerado pelo sensor optoacústico implementado é apresentado na Figura 4. Onde a corrente do sinal gerada pela incidência da luz nos fototransistores do receptor é inicialmente convertida em tensão pelo amplificador de transimpedância. Na sequência o sinal é passado por um filtro passa-altas que tem por função a eliminação do sinal de corrente contínua ocasionado pela iluminação fixa gerada pela barreira de luz, deixando passar apenas o sinal gerado pela variação da luz causada pelo movimento de asas dos insetos. Após o filtro passa-baixas limita a frequência superior do sinal funcionando como um filtro anti-aliasing. Por fim o sinal filtrado é amplificado para o fundo de escala do conversor A/D do bloco do microcontrolador. O bloco do microcontrolador tem por função a realização da conversão 


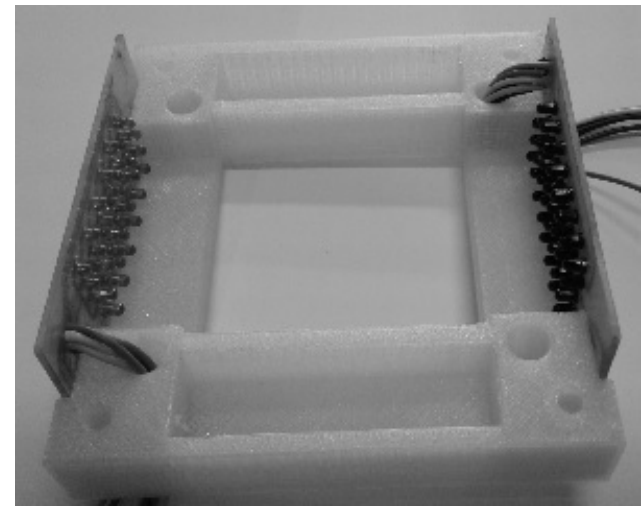

(a) Detalhes da montagem dos circuitos emissor(esquerda) e receptor(direita) na base do sensor optoacústico

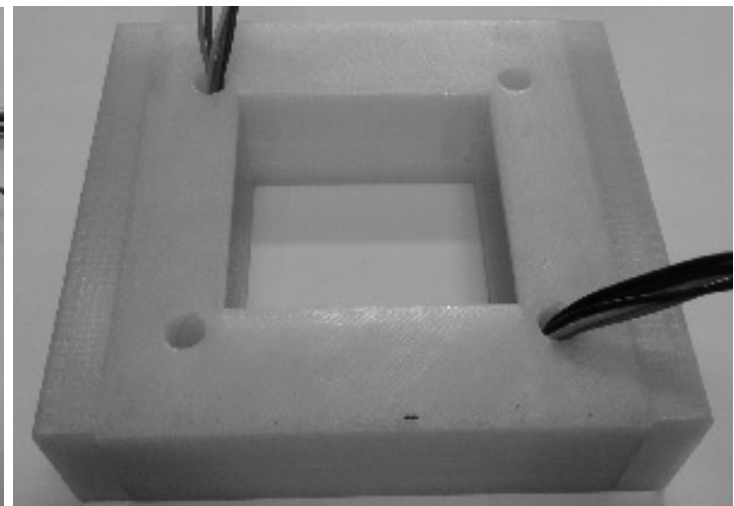

(b) Sensor optoacústico finalizado

Figura 3. Sensor optoacústico construído

para digital do sinal gerado no sensor e realizar o processamento de sinais identificando e contando os insetos. Este bloco também tem a função de transmitir os dados obtidos e realizar o controle do circuito emissor através do bloco Acionamento LED-IR. O bloco Acionamento LED-IR também possui a função de controlar a intensidade luminosa de cada linha da matriz do circuito emissor e ligar ou desligar cada linha independentemente sob o comando do bloco do microcontrolador.

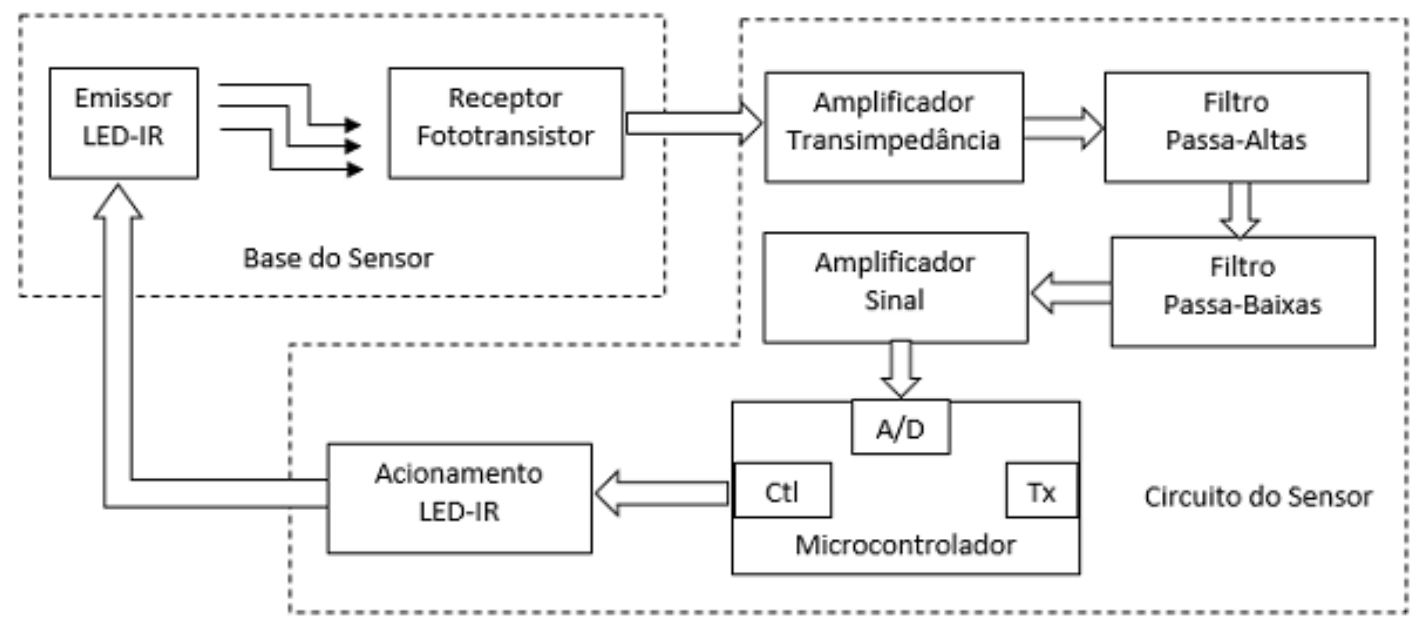

Figura 4. Diagrama em blocos do hardware sensor optoacústico

Os blocos do amplificador de transimpedância, passa-altas, passa-baixas e amplificador de sinal foram implementados utilizando amplificadores operacionais TL082 com alimentação simples de 5V. Estipulou-se o ganho do amplificador de transimpedância como 1000. Os filtros passa-altas e passa-baixas foram especificados utilizando a aproximação Butterworth, implementados com a topologia MFB de segunda ordem, sendo as frequências de corte de $60 \mathrm{~Hz}$ para o passa-altas e de $1000 \mathrm{~Hz}$ para o passabaixas [Pertence Jr 2015]. O amplificador de sinal foi implementado na configuração não-inversor com ganho ajustável de 1 a 101. 
O bloco de acionamento LED-IR consiste em quatro fontes de corrente ajustáveis de $6,62 \mathrm{~mA}$ até $125 \mathrm{~mA}$. Cada uma delas aciona uma linha do circuito emissor do sensor sendo ligadas ou desligadas através do bloco do microcontrolador.

\subsection{Experimentos}

Os experimentos realizados tiveram como objetivos verificar o funcionamento do sensor e sua possibilidade de uso com insetos. Para isto avaliou-se o ruído do sistema, a melhor configuração das matrizes do circuito emissor e receptor e a resposta do sensor a diferentes frequências de estímulo.

Para isto implementou-se um simulador de batimentos de asas de insetos utilizando um motor CC de 12V/6000rpm e um fio com diâmetro de 0,5mm fixado ao seu eixo. Quando o simulador é ativado o motor gira o fio a uma velocidade constante que quando dentro da área de passagem do sensor ocasiona flutuações na luz recebida pelos fototransistores com uma frequência constante determinada pela tensão de alimentação do motor. O simulador acoplado ao sensor optoacústico para realização dos experimentos é apresentado na Figura 5.

Na verificação da frequência de rotação do simulador utilizou-se um osciloscópio Tectronix TBS1062 com largura de banda de $80 \mathrm{MHz}$ e taxa de amostragem de $1 \mathrm{GS} / \mathrm{s}$ conectado a saída do circuito amplificador de sinal.

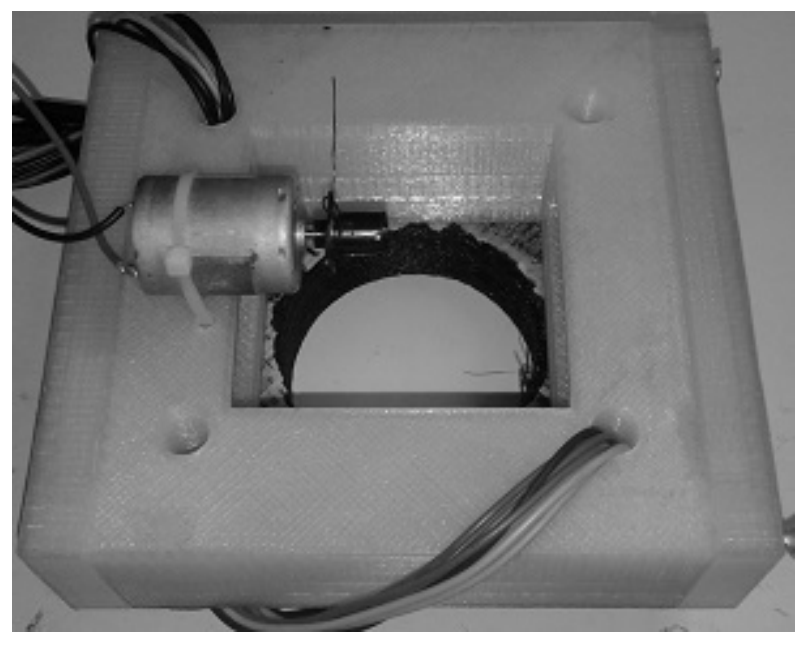

Figura 5. Simulador acoplado ao sensor para realização dos experimentos

Para a aquisição de sinal utilizou-se um notebook Asus K84C Series, com processador Intel(R) Core(TM) i3-2330M 2,20GHz, memória ram de 4,00GB, sistema operacional Windows 7 Home Basic, placa de som Realtek High Definition Audio versão 6.14.0.3097. Realizou-se a aquisição de sinal conectando a saída de sinal do sensor na entrada de microfone do notebook, gravando o áudio gerado com o software Audacity versão 2.1.3 por um tempo de 60s, em arquivos do formato WAV, com uma taxa de amostragem de $44100 \mathrm{~Hz}$, mono e com resolução de 32 bit float.

Utilizou-se o software SciLab versão 6.0.0 para a análise dos áudios capturados. Onde o arquivo WAV gravado é lido e realizada a passagem do domínio tempo para o domínio frequência utilizando a função FFT. Após é gerado o gráfico da energia distribuída no espectro de frequência para análise. 
Os experimentos foram executados com as fontes de corrente que alimentam os LED-IR reguladas em 20mA, com o circuito do sensor com uma tensão de alimentação de 9V fornecida por uma fonte de bancada PS23023, em um laboratório com iluminação produzida por lâmpadas fluorescente tubular com temperatura de cor de 6500k e com um intensidade luminosa sobre o sensor de 7010lux.

\section{Resultados}

Inicialmente avaliou-se o desempenho do sensor em relação as diversas fonte de ruído. Verificou-se o ruído gerado pela iluminação ambiente, o ruído gerado pelo circuito emissor, o ruído gerado pelo hardware do sensor e o ruído ocasionado pela vibração mecânica do simulador quando fixo ao sensor.

Com base nos resultados gerados constatou-se que a principal fonte de ruído foi ocasionada pela rede elétrica com frequência fundamental de $60 \mathrm{~Hz}$, juntamente com suas harmônicas. Um dos gráficos gerados pelo experimento de avaliação do ruído é apresentado na Figura 6(a), onde nota-se o sinal gerado pelo simulador com uma frequência de $134,6 \mathrm{~Hz}$ com amplitude de $0,13 \mathrm{~V}$ e o ruído de $60 \mathrm{~Hz}$ com uma amplitude inferior a $0,01 \mathrm{~V}$.

Com relação as influências dos componentes do sensor constatou-se que a iluminação externa é responsável por 5\% do ruído total, o circuito emissor por $95 \%$ do ruído total e o restante é ocasionado no circuito receptor e no hardware do sensor. Foi observado que a vibração mecânica ocasionada pelo simulador de asas de insetos não gerou ruído considerável.

Para a avaliação da melhor configuração das linhas das matrizes do circuito emissor e receptor realizou-se experimentos com os dois circuitos com quatro linhas, o receptor com uma linha e o emissor com quatro linhas e o receptor com quatro linhas e o emissor com uma linha. Como métrica de avaliação utilizou-se a relação sinal-ruído da intensidade do sinal da frequência fundamental com o simulador com 12V/6000rpm e a intensidade dos sinais de ruído gerados. Obteve-se como resultados:

- Quatro linhas no receptor e quatro linhas no emissor: $S N R(60 H Z)=6,66$ e $\operatorname{SNR}(45 \mathrm{~Hz})=0,375$;

- Uma linha no receptor e quatro linhas no emissor: $\operatorname{SNR}(60 \mathrm{HZ})=2,21$ e $\operatorname{SNR}(45 \mathrm{~Hz})=0,19$;

- Quatro linhas no receptor e uma linha no emissor: $S N R(60 H Z)=43,33$ e $\operatorname{SNR}(45 \mathrm{~Hz})=5,41$.

Baseado nos resultados constatou-se que a melhor configuração foi com o emissor com uma linha e o receptor com quatro linhas. O gráfico gerado com o experimento realizado com essa configuração é apresentado na Figura 6(b), onde nota-se o surgimento de um ruído com frequência de $45 \mathrm{~Hz}$ devido a sobreposição de sinal ocasionada por múltiplas fontes de luz.

Para a análise de desempenho do sensor perante a estímulos de frequências diferentes realizou-se experimentos com o simulador com 4V, 8V, 12V e $16 \mathrm{~V}$. O resultado dos experimentos são apresentados na Figura 6(c). Nota-se que o sensor apresentou uma resposta na frequência fundamental de $177,23 \mathrm{~Hz}$ com $16 \mathrm{~V}, 134,96 \mathrm{~Hz}$ com $12 \mathrm{~V}, 93,48 \mathrm{~Hz}$ com $8 \mathrm{~V}$ e $46,48 \mathrm{~Hz}$ com $4 \mathrm{~V}$, sendo condizente com a frequÃancia dos estÃmulos aplicados. Com relação as suas harmônicas observa-se o decaimento de intensidade com o 
aumento na ordem da harmônica como o esperado, com exceção do sinal de $46,48 \mathrm{~Hz}$ que a sua intensidade é afetada pelo filtro passa-faixas que tem uma frequência de corte em $60 \mathrm{~Hz}$.

Verificou-se a exatidão do sensor optoacústico desenvolvido comparando a frequência fundamental do sinal capturado com o osciloscópio com a resposta na frequência fundamental obtida no processamento do sinal capturado no computador. Obteve-se como resultados, respectivamente no osciloscópio e no computador, $177,9 \mathrm{~Hz}$ e $177,23 \mathrm{~Hz}$ com $16 \mathrm{~V}, 134,6 \mathrm{~Hz}$ e $134,96 \mathrm{~Hz}$ com $12 \mathrm{~V}, 89,9 \mathrm{~Hz}$ e $93,48 \mathrm{~Hz}$ com $8 \mathrm{~V}$ e $44,3 \mathrm{~Hz}$ e $46,48 \mathrm{~Hz}$ com $4 \mathrm{~V}$. O sinal capturado com o osciloscópio estando o simulador com $12 \mathrm{~V}$ é apresentado na Figura 6(d), onde nota-se a distorção harmônica e o valor da frequência fundamental de $134,6 \mathrm{~Hz}$.
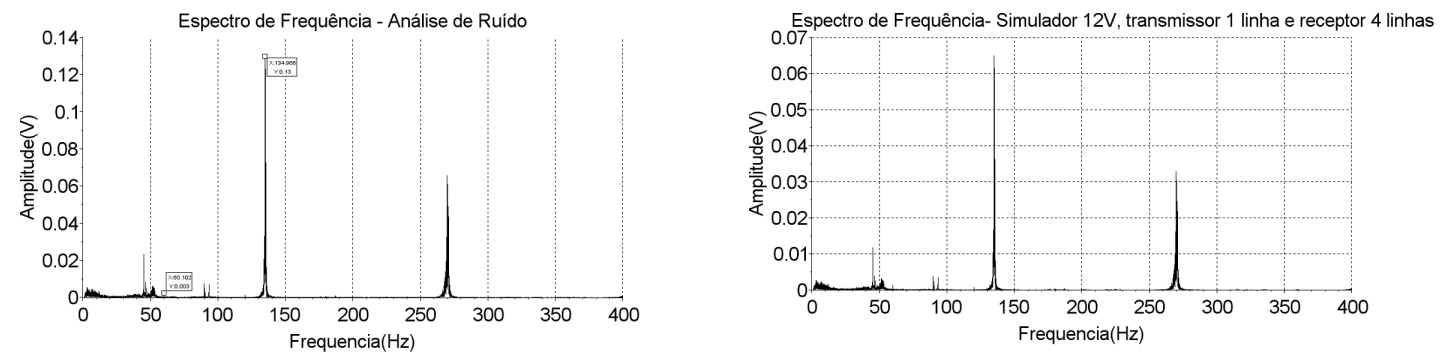

(a) Gráfico do experimento para avaliação do ruído (b) Gráfico do experimento com o emissor tendo com simulador gerando um sinal de 134,6Hz/0,13V quatro linhas e o receptor com uma linha: e ruído com $60 \mathrm{~Hz} / 0,01 \mathrm{~V}$ $\operatorname{SNR}(60 \mathrm{HZ})=43,33$ e $\mathrm{SNR}(45 \mathrm{~Hz})=5,41$ em relação ao sinal de estímulo $134,6 \mathrm{~Hz} / 0,065 \mathrm{~V}$
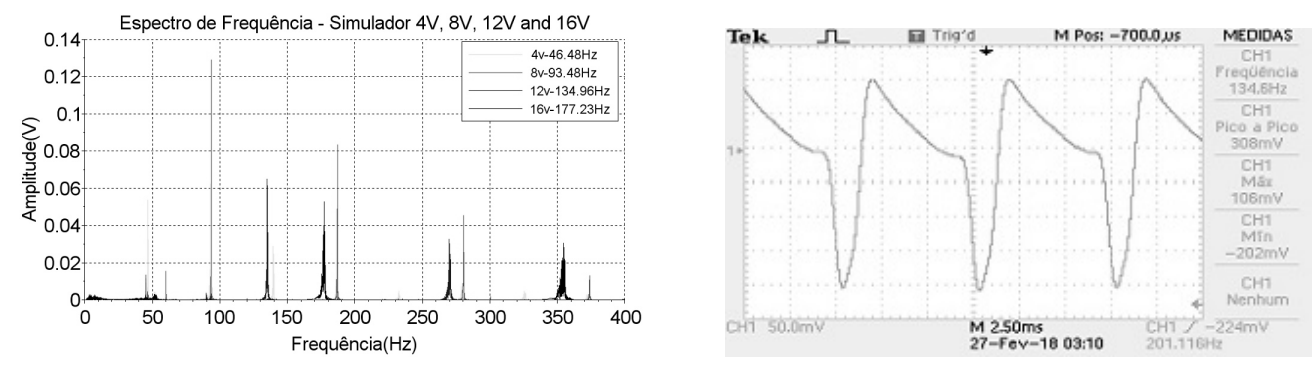

(c) Gráfico do experimento para avaliação do de- (d) Sinal capturado no osciloscópio com sempenho em estímulos com frequências diferentes o simulador em $12 \mathrm{~V}$, utilizado como referência para avaliação da exatidão do sensor

Figura 6. Resultados dos experimentos realizados

\section{Conclusão}

Neste trabalho apresentou-se o desenvolvimento de um sensor optoacústico para uso em armadilhas inteligentes para moscas-das-frutas $C$. capitata e A. fraterculus.

Com base nos experimentos realizados o sensor optoacústico desenvolvido mostrou-se praticamente imune aos ruídos oriundos do ambiente e com uma exatidão superior a 95\%. Apresentando uma identificação correta dos sinais até sua quinta harmônica

Assim, levando em consideração que conforme [Potamitis et al. 2017] e [Malavasi and Aquino 1996] a frequência fundamental das asas da mosca C. capitata é 
de aproximadamente $200 \mathrm{~Hz}$ e da mosca A. fraterculus é de aproximadamente $90 \mathrm{~Hz}$ o que pode ser simulado aproximadamente com o simulador com $8 \mathrm{~V}$ e $16 \mathrm{~V}$. O sensor mostrouse promissor para experimentos com insetos, identificando corretamente até sua quinta harmônica.

\subsection{Trabalhos futuros}

Para os trabalhos futuros pretende-se:

- Realizar a captura de sinais em laboratório utilizando moscas criadas em cativeiro e capturadas no meio ambiente;

- Estudo de outras técnicas de obtenção do espectro de frequência de um sinal como séries de Fourier e transformada Wavelet;

- Estudo sobre técnicas de reconhecimento de voz para serem aplicadas ao reconhecimento de insetos;

- Desenvolvimento de uma armadilha inteligente utilizando detecção optoacústica em tempo real de insetos utilizando o sensor desenvolvido.

\section{Referências}

Gebbers, R. and Adamchuk, V. I. (2010). Precision agriculture and food security. Science, 327(5967):828-831.

Liu, H., Lee, S.-H., and Chahl, J. S. (2017). A review of recent sensing technologies to detect invertebrates on crops. Precision Agriculture, 18(4):635-666.

Malavasi, A. and Nascimento, A. (2003). Programa biofábrica moscamed brasil. Simpósio de Controle Biológico, 8:52.

Malavasi, R. M. A. and Aquino, C. (1996). Acoustical comparisons of calling songs from anastrepha species in brazil. Fruit Fly Pests: A World Assessment of Their Biology and Management, page 37.

MAPA (2015). Agricultura destina $\mathrm{r} \$ 128 \mathrm{mi}$ contra moscas-das-frutas. http://www.brasil.gov.br/economia-e-emprego/2015/09/agricultura-destina-r-128mi-contra-moscas-das-frutas. Acessado em 27 outubro 2017.

Meng, X., Liu, Y., and Sun, M. (2017). Aerodynamics of ascending flight in fruit flies. Journal of Bionic Engineering, 14(1):75-87.

Nava, D. E. and Botton, M. (2010). Bioecologia e controle de anastrepha fraterculus e ceratitis capitata em pessegueiro. Embrapa Uva e Vinho-Documentos (INFOTECA-E).

Pertence Jr, A. (2015). Amplificadores Operacionais e Filtros Ativos - 8 ed. Bookman Editora.

Potamitis, I., Rigakis, I., and Fysarakis, K. (2014). The electronic mcphail trap. Sensors, 14(12):22285-22299.

Potamitis, I., Rigakis, I., and Tatlas, N.-A. (2017). Automated surveillance of fruit flies. Sensors, 17(1):110.

Unwin, D. and Ellington, C. (1979). An optical tachometer for measurement of the wingbeat frequency of free-flying insects. Journal of Experimental Biology, 82(1):377-378.

Vogel, S. (1966). Flight in drosophila. Journal of Experimental Biology, 44(3):567-578. 